\title{
How to Stimulate the Water and Agriculture Nexus?
}

\author{
Rob van der Veeren ${ }^{1}$, Diederik van der Molen ${ }^{2}$ and Siep Groen ${ }^{3}$ \\ 1. Rijkswaterstaat, Lelystad 8200 AA, The Netherlands \\ 2. Ministry of Infrastructure and Water Management, The Hague 2500 EX, The Netherlands \\ 3. Ministry of Agriculture, Nature and Food Quality, The Hague 2500 EK, The Netherlands
}

\begin{abstract}
Water and agriculture are interlinked: water is indispensable for agricultural production and agricultural production results in emissions of nutrients and other substances to surfacewater and groundwater. However, not only in physical terms are water and agriculture interlinked, there are also strong links between water and agricultural policies. This paper focuses on European National Policies on water and agriculture. Agricultural practices are primarily regulated by European Agricultural Policies, such as the Nitrate Directive, Directive 2009/128/EC on sustainable use of pesticides and the Common Agricultural Policies. The achievement of the objectives for nutrients and pesticides of European water related policies, such as the Drinking Water Directive and the Water Framework Directive, depends on agricultural practices. Therefore, for an effective and efficient implementation of sustainable policies on both agriculture and water, it is necessary to make sure that the targets and instruments of the two policy areas are properly aligned. Current practices show that this is not yet the case; so, there is room for improvement. This paper highlights steps needed to improve cooperation between these two policy domains and discusses first steps already taken at the European level. In addition, some examples of Dutch National Initiatives resulting from a dialogue between farmers and water managers with the aim of combining the objectives of water and agricultural policies and interests are presented.
\end{abstract}

Key words: European Policies, agriculture, water.

\section{Need for Alignment of European Water and Agricultural Policies}

This section describes some of the problems national water and agricultural authorities run into when trying to implement European Water and Agricultural Policies. This is done using three cases as illustration: nutrients, crop protection products and nature.

\section{Case 1: Nutrients}

Some of the most relevant European Policies related to nutrients are the WFD (Water Framework Directive), with its focus on sustainable use of water and a good status for ecology, the ND (Nitrates Directive), which aims at reducing and preventing nutrient emission to groundwater and surface waters, and the DWD (Drinking Water Directive), which

Corresponding author: Rob van der Veeren, Ph.D., senior policy advisor, research field: economic analyses and financing in water management. deals with the protection of human health. These directives have different objectives and use different instruments. The European Commission is clear: "member states should reach all objectives". Referring to article 11 of the Water Framework Directive [1], it is up to the member state to decide whether measures to decrease eutrophication are part of an Action Program under ND or as additional measures within the WFD. This leaves room for member states to optimize their program of measures. But at the same time, it turns out to be very difficult to get (political) support for additional WFD measures related to agricultural emissions, on top of measures based on agricultural policies, which are, according to farmers' organisations, already harsh. This difficulty to combine programs also has to do with policy developments over time and the necessity to give farmers some time to be able to adjust to those policy developments. The ND, for example, focuses on reducing agricultural nutrient emissions to water. This 
goal was first formulated in terms of a standard for groundwater. After some time, farmers have adjusted their practices to meet these standards. Some years later, WFD targets for surface waters were established. These targets can be translated into stricter ND standards for surface water and additional measures in Nitrate Action Plans. Farmers will need some time to understand the meaning of such ND surface water standards and to adjust their farm practices accordingly.

\section{Case 2: Crop Protection Products}

For crop protection products, the authorization of selling crop protection products on the market, the use of crop protection products and the control of water pollution are regulated by European Policies (including Regulation (EC) No 1107/2009 of the European Parliament and of the Council of 21 October 2009 concerning the placing of plant protection products on the market [2], Regulation (EU) No 528/2012 of the European Parliament and of the Council of 22 May 2012 concerning the making available on the market and use of biocidal products [3], and Directive 2009/128/EC of the European Parliament and of the Council of 21 October 2009 establishing a framework for Community action to achieve the sustainable use of pesticides [4], WFD [1] and DWD [5]). More than once, situations arise in which certain crop protection products have to be admitted to the market, since there is no legal ground to ban them, which cause water quality standards to be exceeded, once the products are used. This means that these substances first have to affect the environment before member states are allowed to further control the use of these substances or even ban them from the market. This is a rather inconvenient situation for many water managers. For individual member states, it is very difficult to get political support for additional unilateral measures on the use of those substances, since farmers' organizations will use the level playing field argument in order to plea against such unilateral measures. In addition, unilateral bans may not be very effective, as long as farmers can easily import substances from other European countries.

\section{Case 3: Nature}

The BHD (Bird and Habitat Directives) focusses on the protection of specific species and areas. The WFD aims to improve the protection of waters in terms of quantity and quality, to promote sustainable water use and to protect aquatic ecosystems and terrestrial ecosystems and wetlands that directly depend on water. Good quality and quantity of groundwater and surface water will contribute to securing the drinking water supply for the population.

Sometimes, species or areas have a natural value based on habitats which developed in heavily modified or artificial waterbodies. For example, reversed water level fluctuation in lakes may be beneficial for ducks and swans feeding on macrophytes in spring. Black-tailed godwit (Limosalimosa) is dependent on specifically managed agricultural areas within surface waterbodies. Where a Natura 2000-area is part of a surface waterbody, it is in practice difficult to determine which water quality standard has to be achieved. In general, the WFD requires a reduction in nutrient loads to reduce eutrophication, but the protection of the population of certain species under the BHD requires eutrophic waters and therefore to maintain the nutrient loads. There is not only a difference in objectives (natural development of species and habitats in surface waters of good ecological status versus protection of species and habitats present through spatially limited areas in the same surfacewaters) that causes challenges. There are also different spatial requirements and deadlines, which make it difficult for member states to tackle problems and to comply with both directives at the same time.

\section{The Way Forward}

\subsection{Common Language}

The examples presented above illustrate that for a 
proper implementation of EU legislation, at both Member State and Commission levels, water and agriculture administrations need to be fully engaged. This starts with communication, a language that is understood by representatives of both the water and agricultural side. For example, what is a nutrient problem? For a farmer, this is a shortage of nutrients in the soil which limits agricultural production. But for a water manager, it is an excess amount of nutrients causing eutrophication in rivers and lakes.

\subsection{Common Vision}

The next step is to develop a common vision. There is a need for shared goals from the perspective of agriculture and water management, but also other sectors. If sustainability is the common vision, it should be clear what exactly this vision entails for agriculture. Does it mean an economic activity that provides enough income for farmers to live from, not only today but also in the years to come? Or does it refer to stewardship of rural areas and communities? Or does it mean food production in accordance with limits set by the environment (e.g. water quality, but also air quality and soil status, biodiversity, animal welfare, human health, etc.)?

It is also important to explain what the vision of sustainability means for water management. Does it mean a water system quality that is suitable for economic use? Or does it mean a water system quality that is suitable for protecting ecological values? Or does it mean that good quality water systems and good ecosystems are the basis for well-being and prosperity, thereby imposing conditions for economic use?

A common vision would be helpful for farmers and water managers, as they now sometimes face contradicting demands from different sectors. Such a common vision should also include agreement on how much environmental impact of economic sectors upon water bodies is seen as acceptable and inevitable.

\subsection{Common Agenda}

As a first step to stimulate the debate between the people involved in water related policies and those involved in agricultural policies, the Netherlands as part of their EU presidency in the first half of 2016, initiated the development of a joint water and agriculture agenda. It was decided to start with good practice cases that might be of interest to both areas (win-win situations). Furthermore, a questionnaire was send to water directors and agricultural directors of the European Member States, asking for interesting topics for a first meeting, but also as a start to bring representatives of water directors and agricultural authorities together. Twenty-one member states responded to the questionnaire, but only in a few cases were answers agreed upon between the different authorities within the member state. An important result of the questionnaire was that respondents felt a need for more effective integration of water policies and agriculture policies (at both national and EU levels). And with respect to topics, water quantity, soil management (water quality, nutrients) and pricing were considered to be the most relevant for future discussions [6, 7]. Based on the results of this questionnaire, the water directors at their meeting in Amsterdam in June 2016 agreed to have an expert meeting in Bratislava in October 2016 to prepare a special joint directors meeting on the 8th of May 2017 in Brussels [8].

At the expert meeting in Bratislava, many things were discussed, which resulted in a large list of conclusions [9]. One of the conclusions, which relates to the problems discussed above, is that there is a strong need for an alignment of policies [9]. It was also mentioned that directives are working on paper, but the implementation is often a problem. One of the solutions discussed at that meeting was a better enforcement of legal obligations [9]. But that is focusing on the stick. One could also incentivize farmers to contribute to the improvement of waters (quantity and quality) - by making improving water 
status profitable for farmers [9]. Appropriate water conditions for agriculture enables farmers to minimize the emissions of nutrients. Some other options that were mentioned at that meeting were the involvement of not only the farmers, but also of markets, consumers, and retail industry who could help by shifting the demand for environmentally and locally produced food [9]. Another important topic that was discussed was further greening of the CAP (Common Agricultural Policy), which could be used to offer and increase financial incentives for farmers to produce more environmentally friendly [9].

On the 8th of May 2017, the joint meeting of the water directors and the agriculture directors took place in Brussels [10]. At that meeting, the participants first identified the main bottlenecks on agriculture-water governance at Member State level. These bottlenecks include, amongst others, the lack of connection between respective authorities in the agricultural and water sectors, which hampers the definition of a common direction for both sectors; different competencies at national, regional and local levels; and the complexity of existing EU funding schemes. Furthermore, scarcity of water resources was dominant in many southern European Member States, while problems with water quality were more dominant in many northern European Member States [10].

At their meeting in Malta in June 2017, the water directors were very supportive of further work on the water and agriculture nexus [11]. Key areas for concrete next steps were mentioned: policy implementation, investment and knowledge development. In addition, the need to develop a common vision within the water and agriculture community on what constitutes sustainable agriculture and water management was highlighted. The next Trio-Presidency (Estonia, Bulgaria and Austria) will continue to support this process [11].

Finally, the summary of the joint meeting of the water directors and the agriculture directors was presented at the Informal Agricultural Council, which took place in Malta on 21-23 May 2017 [12]. At that meeting, the Agriculture Ministers from across the EU discussed the inter-relationships between water as a scarce resource, climate change and their impact on agriculture. Phil Hogan, the EU Commissioner for Agriculture gave a speech in which he underlined the importance of the cooperation between agriculture and water. Just a couple of quotes [13]:

- 'I am particularly pleased to be joined here today by good friend and colleague, Commissioner Vella. Our joint participation in your meeting is a clear indication of our shared commitment to addressing the issues of agriculture, sustainable water management and food security.'

- 'If we want to meet the global demand for more and better food, we need to join efforts and work hard to make agriculture more productive but also more resource-efficient.'

- 'In this context, it is not alone welcome but essential that the issues of water and agriculture receive growing attention in the international agenda.'

- 'We have joined forces to establish a "Task Force on Water"... This joint initiative is, for the first time, bringing together a Commissioner for the Environment and a Commissioner for Agriculture to discuss with you the clear linkages between agriculture and water.' (see Textbox 1 for some conclusions of this task force).

The European Commission took the opportunity to discuss at a high-level the joint efforts identified in the recently launched Commission Staff Working Document on Water and Agriculture, which among other things underlines the need to leverage existing and new financial possibilities for investment, for knowledge sharing and for adaptation of the farming sector in this field. The debate also highlighted the need to further work on and discuss two key priorities identified by the Commission [12]: 
- The CAP needs to allow farmers to transition to agro-ecological principles in a cost-effective way;

- The CAP and WFD need to continue to be better aligned in terms of objectives and delivery mechanisms, possibly with greater focus on results and performance.

The Ministers of the various member states stressed that the role of the financial sector is key, as is the need to leverage existing and new instruments and financing sources both within and outside the CAP. In addition, the regional differences in the effects of climate change, temperatures and precipitation, as well as the differences in the availability for farmers of water resources and different soil management practices, which present different challenges in the different regions, require tailor made solutions and flexibility in the instruments applied.

- Current EU agricultural and water legislation provides a wide variety of policy tools which could substantially help achieve good water status.

- Moreover, several other Commission initiatives such as the Investment Plan for Europe, the Circular Economy Action Plan and climate policies also provide a valuable contribution to this goal.

- For meaningful and immediate response to the challenges for agriculture and water sustainability, the above mentioned opportunities for improved implementation, better governance, targeted investments, and reinforced knowledge base should be used.

- The Commission's leadership in achieving the sustainable development goals will be reflected in all these areas.

- In this context, a wider reflection and discussion with the different stakeholders to identify possible ways forward will be important.

Textbox 1 Some conclusions of the joint task force [14].

\section{Good Practices from the Netherlands}

In this section, some examples are presented of projects in the Netherlands where water and agricultural interests are combined to the benefits of both, since they improve agricultural production while at the same time reduce environmental pressures. This section only allows for a very short description of a limited number of examples out of many projects that already take place in the Netherlands. These projects are included as tailor made solutions in both the Nitrate Action Plan (agricultural policies) and the 'Delta Approach Water Quality and Fresh Water' (a Dutch water policy process). These projects are, therefore, examples of the results of a combination of water and agricultural policies and interests based on a dialogue between farmers and water managers.

\subsection{Reduction of Soil Compaction by Using Lighter Machinery}

In fertile areas with heavy clay soils, heavy machinery may cause compaction. Once compaction has taken place, it results in serious and long lasting problems: more run-off and less uptake of nutrients (manure, fertilizer) by crops. Therefore, lighter machinery is important to prevent future problems [15].

\subsection{Agriculture at the Required Level}

Even in a flat country such as the Netherlands, there are sometimes differences of several meters altitude, even in one farmer's land. For example, on the sandy soils in the eastern part of the Netherlands, also as a result of climate change, farmers are confronted with both wetter and dryer conditions. This not only poses problems for farmers, but also to the regional water authorities and all users in the area. Likewise, there are significant variations in soil types and mechanization. Due to these variations, a one-size-fits-all solution will not be appropriate. Therefore, it's necessary to produce tailor-made measures and solutions. For this, integration of soil and water management is essential. This is not just a water matter, but also a matter of clever business. As a result of the integrated water and soil measures that are part of the project 'Agriculture at the required level', farmers can achieve 1-10\% more crop yield, for example by implementing Climate Adaptive Drainage. 
This is a special type of adjustable drainage, which is meant to fulfil two objectives: storage of water in dry times and reduction of peak discharge in the soil through handling extreme precipitation events. This is only one example of many projects where regional water authorities, farmers and researchers have worked together for water-conscious farming, implemented innovations and shared experiences, whilst always keeping an eye on each other's interests. These projects have shown that deliberate consideration of the consequences of climate change can lead to much creativity and inventiveness, and have resulted in practical and applicable pointers in the area of soil and surface, hydrology, crop selection and business operation, which are described in "Soil and Water Optimization" [16].

\subsection{A More Intensive Drainage System Has Multiple Benefits}

A more intensive drainage system has various advantages: it increases drainage, reduces pests and diseases due to wet conditions in the soil, increases aeration of the soil, increases root development, reduces nitrogen losses due to denitrification, increases water retention capacity and reduces stream velocity of groundwater and therefore reduces nutrient losses [17].

\subsection{Fertile Recycling Agriculture: A Mineral Accounting System that Raises Awareness}

By using a mineral accounting system, dairy farmers get suggestions on where there might be room for improvement. For example, grass yields increased significantly by performing soil tests, which indicated the need to increase $\mathrm{pH}-$ level [18].

Another example: nitrogen losses reduced and money was saved by shifting from corn to fodder beets, which have a significantly higher nitrogen uptake. This resulted in less nitrogen losses after the growing season and higher yields, which more than compensated for the higher costs [19].

\section{Summary, Discussion and Conclusions}

This paper has stressed the importance of stimulating the water-agriculture nexus. It started off by presenting some of the problems national and regional authorities run into when trying to comply with various pieces of legislation. It then described the process to improve mutual understanding and the way forwards. Finally, some Dutch examples showed what a dialogue between farmers and water managers can bring, when water and agricultural policies and interests can be combined in practical projects that improve agricultural production while at the same time reducing environmental pressures.

This paper indicated some boundary conditions for further cooperation. It all starts with talking to each other. For this, it is important to agree upon one common vision, align definitions and guiding principles, such as sustainable agriculture, and to acknowledge each other's objectives and interests. Furthermore, it is important to be aware that farmers not only have to comply with various environmental standards, but also with food security, labor related legislation, etc.. Here a common vision is indispensable. Because this is difficult, a start may be made by sharing good practices and showing results. With respect to this, it is worthwhile to mention that the overall assessment of the status of water bodies under the WFD, based on the "one-out-all-out" principle, is detrimental to get support for environmental measures, since the method does not give a representative picture of the present status and is not susceptible to changes in the status of water bodies.

Another important impetus for good practice is money. The upcoming negotiations on the renewal of the Common Agricultural Policy are an ideal opportunity to align water and agricultural policies in terms of objectives and delivery mechanisms, with a greater focus on results and performance. This could be done by adjusting agricultural policies and funding in a way that allows and stimulates farmers to make 
the transition towards more environmental friendly production in a cost-effective way by applying tailor made solutions. Now is the time to show that the water and agricultural nexus that was built over the past years, is not just nice words, but really delivers effective results for both farmers and the environment.

\section{References}

[1] European Parliament, Council of the European Union. 2000. "Directive 2000/60/EC of the European Parliament and of the Council of 23 October 2000 Establishing a Framework for Community Action in the Field of Water Policy." Accessed August 8, 2017. http://data.europa.eu/eli/dir/2000/60/oj.

[2] European Parliament, Council of the European Union. 2009. "Regulation (EC) No 1107/2009 of the European Parliament and of the Council of 21 October 2009 Concerning the Placing of Plant Protection Products on the Market and Repealing Council Directives 79/117/EEC and 91/414/EEC.” Accessed August 8, 2017. http://data.europa.eu/eli/reg/2009/1107/oj.

[3] European Parliament, Council of the European Union. 2012. "Regulation (EU) No 528/2012 of the European Parliament and of the Council of 22 May 2012 Concerning the Making Available on the Market and Use of Biocidal Products." Accessed August 8, 2017. http://eur-lex.europa.eu/eli/reg/2012/528/oj.

[4] European Parliament, Council of the European Union. 2009. "Directive 2009/128/EC of the European Parliament and of the Council of 21 October 2009 Establishing a Framework for Community Action to Achieve the Sustainable Use of Pesticides." Accessed August 8, 2017. http://data.europa.eu/eli/dir/2009/128/oj.

[5] European Parliament, Council of the European Union. 1998. "Council Directive 98/83/EC of 3 November 1998 on the Quality of Water Intended for Human Consumption." Accessed August 8, 2017. http://data.europa.eu/eli/dir/1998/83/oj.

[6] European Commission. 2016. "Results of the Questionnaire on the Development of a Joint Water Agriculture Agenda." Accessed August 8, 2017. https://circabc.europa.eu/sd/a/7608a15e-df5a-472b-a874ef6d1 fbcbd41/WD2016-1-6\%20Item\%2012.b)\%20-\%20 AnnexI-Results\%20of\%20the \%20questionnaire\%20joint \%20Water\%20Agri\%20meeting-v2.docx.

[7] European Commission. 2016. "Towards a Joint Agenda for the Water and Agriculture Directors." Accessed August 8, 2017. https://circabc.europa.eu/sd/a/e93c119c-06ce-4f67-a8462293894759d0/WD2016-1-6\%20Item\%2012.b)\%20-\%20
Cover\%20note $\% 20-\% 20$ Towards $\% 20 a \% 20$ joint $\% 20$ agen da $\% 20$ for $\% 20$ the $\% 20$ Water $\% 20$ and $\% 20$ Agriculture $\% 20$ Directors-final.docx.

[8] European Commission. 2016. "Final Synthesis of the Informal Meeting of Water and Marine Directors of the European Union, Candidate and EFTA Countries Amsterdam, 9th and 10th of June 2016." Accessed August $\quad 8$, 2017. https://circabc.europa.eu/sd/a/d1bbf29a-b949-4601-bc2ad5091fddbe6a/Final\%20synthesis\%20WMD\%20Amsterd am.docx.

[9] European Commission. 2016. "Draft Minutes of the Workshop on Water and Agriculture: Enhancing Cooperation between Water and Agriculture Stakeholders to Deliver Sustainable Agriculture and Healthy Waters." $\begin{array}{llll}\text { Accessed } & \text { August } & \text { 8, }\end{array}$ https://circabc.europa.eu/sd/a/d3f2d0ba-053f-4992-b8097149602abd52/Minutes\%20\%20Workshop\%20Water\%2 0and\%20Agriculture\%2024\%20Oct\%202016..docx.

[10] European Commission. 2017. "Presidency Document: Outcome of the Water and Agriculture Directors Meeting." Accessed August 8, 2017. https://circabc.europa.eu/sd/a/23c4c912-c83e-4ff5-9e65-5 $18 \mathrm{c} 7 \mathrm{a} 5646 \mathrm{bd} /$ Outcome\%20Water\%20and\%20Agricultur e\%20Directors_20_05_2017.docx.

[11] European Commission. 2017. "Final Synthesis of the Informal Meeting of Water and Marine Directors of the European Union, Candidate and EFTA Countries, Malta, 15 and 16 June 2017." Accessed August 8, 2017. https://circabc.europa.eu/sd/a/5f9e26cb-59b7-44ef-b03a-a 3970964a58f/Malta\%20WMD\%20outcomes.pdf.

[12] European Commission. 2017. "Press Release on Informal Meeting of Agriculture Ministers, Malta, 23 May 2017." Accessed August 8, 2017. http://www.eu2017.mt/en/Press-Releases/Documents/PR 230517_EN.pdf.

[13] European Commission. 2017. "Speech by Commissioner Phil Hogan at Informal Meeting of Agriculture Ministers-Malta, 23 May 2017.” Accessed August 8, 2017.

https:/ec.europa.eu/commission/commissioners/2014-20 19/hogan/announcements/speech-commissioner-phil-hog an-informal-meeting-agriculture-ministers-malta-23-may2017_en.

[14] European Commission. 2017. "Commission Staff Working Document; Agriculture and Sustainable Water Management in the EU." Accessed August 8, 2017. https:/circabc.europa.eu/sd/a/85e92939-c01c-4bfe-8e2ea3c571ccc459/SWD_2017_EN_V4_P1_885057.pdf.

[15] Lerink, P. 2015. "Light Work with Heavy Machinery." Accessed August 8, 2017. http://hwodka.nl/index.php/23-licht-werk-met-zware-mac 
hines.

[16] 'Agriculture at the Required Level' Project. 2014. "Soil and Water Optimization." Accessed August 8, 2017. http://landbouwoppeil.nl/publish/pages/19701/soil_and_ water_optimisation.pdf.

[17] Lerink, P., and Klompe, A. 2016. "Back to the Roots: Vision and Plan for an Integrated Approach for Sustainable Soil Management.” Accessed August 8, 2017. http://hwodka.nl/images/HW2O_verslag_160315_definiti ef.pdf.
[18] Fertile Cycle Achterhoek and Liemers. 2016. "Stories of Real Life Experiences: Martijn Kornegoor." Accessed August 8 , 2017. http://vruchtbarekringloopachterhoek.nl/portfolio-items/ martijn-kornegoor/.

[19] Fertile Cycle Achterhoek and Liemers. 2016. "Stories of Real Life Experiences: Arjan Freriks.” Accessed August 8 , 2017. http://vruchtbarekringloopachterhoek.nl/portfolio-items/a rjan-freriks-2. 